\title{
The sustainability of biodynamic horticultural production: the case of Po valley
}

\author{
G. Ferrazzi, S. Bormolini, G. Agnelli and V. Ventura \\ Department of Economics, Management and Quantitative Methods, Università degli Studi di Milano, Italy.
}

\begin{abstract}
More and more attention is paid to environmental, economic and social sustainability of the agricultural activity as it is proved at European level by the new setting of CAP toward 2020. It is therefore interesting to understand which production practices better react to these characteristics. Biodynamic appears to respond well in terms of environmental sustainability: can the same be affirmed in terms of economic sustainability? In this paper Italian biodynamic sector has been analyzed focusing on horticultural production: its economic sustainability has been verified especially for small farms that are facing increasing problems in terms of profitability. The Italian Demeter database was used to identify biodynamic farms that have been georeferenced at a national level and then only the ones specialized in vegetable production have been selected for Italy. In order to assess its economic sustainability the production costs for three farms located in the area of the High Po valley that are converting from organic to biodynamic have been examined, focusing on five items: lettuce (Lactuca sativa), tomato (Solanum lycopersicum), zucchini (Cucurbita pepo), eggplant (Solanum melongena), cucumber (Cucumis sativus). Then these costs have been compared to the ones associated with organic and traditional methods. Their prices have been also compared in order to achieve an economic assessment of the different production methods. Finally a SWOT analysis regarding the adoption of the biodynamic method has been performed. This paper proves that the biodynamic method is economically sustainable in the horticultural production based on higher retail prices that - for some products - compensate higher costs, in comparison to the organic and traditional methods. Another factor that strengthens the use of the biodynamic method is a favorable European legislation.
\end{abstract}

Keywords: biodynamic agriculture, economic profitability, productive methods, farm strategies, supply chains

\section{INTRODUCTION}

The agricultural productive model derived from Green Revolution has allowed a considerable growth in agricultural production (Hazell, 2003; Pingali, 2012). However, it brought high levels of negative environmental externalities too, like loss of biodiversity, water contamination, soil erosion and consequences on human health caused by the use of chemical products (Pimentel et al., 2005; Pretty, 2008; Tilman et al., 2011). The destabilization of the ecosystem services and the loss of resilience in agricultural systems is affecting the response to environmental changes (Swift et al., 2004) determining, along with the high input levels in conventional agriculture, economic and social costs that reduce the advantage derived from a higher production (Pretty, 2008). For this reason many authors (Tisdell, 2005; Foley et al., 2011) assert the long-term unsustainability of this productive model. Though food security remains the main global goal for a growing world population, authors and institutions calls for a more sustainable - low input - vision of agriculture (FAO, 2011). Over the last 10 years alternative productive models have emerged, such as integrated system, conservative agriculture, organic agriculture and biodynamic system, that though presenting substantial technical differences, they all share the aim to refuse conventional - high input - agriculture. The main difference is the ban of the use of agrochemicals and genetically modified organisms (GMOs) that separates organic and 
biodynamic agriculture from integrated and conservative methods (Table 1 ). The identification of these two groups of agricultural practices is also confirmed by the "specialized sales channel" variable that reveals, for organic and biodynamic methods, the propensity to create ad hoc, often short, supply chains. In parallel, the growth of the interest in sustainable agriculture and in healthiness of its product within scientific community and civil society is remarkable (Zander and Hamm, 2010; van Doorn and Verhoef, 2011; Hjelmar, 2011). The organic and sustainable products market has generally grown all over Europe in the past few years and this sensibility is reflected in the Common Agricultural Policy (CAP) which aims to implement sustainable and organic practices in 2013-2020 Planning. This recent consumers' attention is developing local markets too, with direct sales in farm and the preference for organic products (Brown et al., 2009).

Table 1. Sustainable agricultural practices: similarities and differences.

\begin{tabular}{lcccc}
\hline & $\begin{array}{c}\text { Integrated } \\
\text { agriculture }\end{array}$ & $\begin{array}{c}\text { Organic } \\
\text { agriculture }\end{array}$ & $\begin{array}{c}\text { Conservative } \\
\text { agriculture }\end{array}$ & $\begin{array}{c}\text { Biodynamic } \\
\text { agriculture }\end{array}$ \\
\hline Birth decade & 80 & 70 & 60 & 20 \\
Rotation and other similar techniques & yes & yes & yes & yes \\
Pesticides and other chemicals & yes & no & yes & no \\
Extra agriculture factors (moon phases) & no & no & no & yes \\
Use of vegetal preparation & no & no & no & yes \\
GMOs use propensity & yes & no & yes & no \\
European common regulation & Directive & Directive/2007I & no & no \\
Internal regulation & $2009 / 128 / E C$ & $834 / E C$ & Jager institute, & Demeter \\
& no & no & ASMEDIA & international \\
Specialized sales channels & no & yes & no & yes \\
\hline
\end{tabular}

Italy is one of the European countries with the fastest growing organic production and consumption. Though a long period of strong economic crisis which has involved almost all economic sectors, the organic market has reached $a+17.4 \%$ increase in the first four months of 2014 , with a $+5.8 \%$ of employed and $+5.5 \%$ of cultivated land by comparison with 2013 , while the whole agricultural branch has scored a $1.4 \%$ decrease in the same period (SINAB, 2014). The organic market share in 2013 was 3,1 billion euros, corresponding to $5.5 \%$ of total agricultural production value, as emerged from a report of the Istituto di Servizi per il Mercato Agricolo Alimentare (ISMEA, 2013). We can only presume that biodynamic market shows a similar trend as the organic one because, unfortunately, statistical data about this sector are hardly available in official Italian statistical organisms. Demeter database identifies 400 biodynamic farms in Italy in 2014 with 8,934 ha of cultivated land (www.demeter.net), making Italy the third European biodynamic producer after Germany and France. Environmental sustainability is a constitutive characteristic of biodynamic method. One of the nodal points of this theory is to consider the farm as a unique and independent corpus which can minimize energy inputs from the exterior (Reganold et al., 1993).

Can the same also be true in terms of economic sustainability? This article investigates the economic profitability of biodynamic farms in a specific agricultural branch, that is horticulture, which in Italy has 6.86 billion euro of economic value, corresponding to $24.7 \%$ of total agricultural value, and which employs 66,900 workers (source: ISTAT). Moreover we analyzed the economic convenience of biodynamic choice focusing on a particular economic context, the small farm, that, though they constitute a key factor in developing local food systems, are facing increasing problems in terms of profitability.

\section{MATERIALS AND METHODS}

The identification of the biodynamic firms in Italy (producers and processors) has been performed through the Demeter International Database. In order to create a map of 
these farms at national level and to evaluate the characteristics of their distribution, the software ArcGIS has been used (Figure 1). We analyzed a specific economic and social context, that is Po Valley, the main Italian plain that includes four regions with similar environmental and economic characteristics. Here different kinds of agricultural systems coexist. On one hand we find an industrial agriculture, increasingly concentrated in new market competitive and technologically specialized organizations. For example, regarding the horticultural sector, the second level organization AOP1 Lombardia gathers many producer organizations achieving a strong economic and market power (Frisio et al., 2012). On the other hand the small farms that are facing increasing difficulties in terms of economic sustainability and access to markets, for which the conversion to other types of agricultural production, able to meet specific market requirements, can be an alternative solution. Northern Italy already has a high concentration of organic specialized shops: in $201365 \%$ of them were situated in Italian northern regions (MIPAAF, 2013), showing greater levels of both environmental sensibility and financial means of consumers. Three small farms in the process of converting from the organic to biodynamic method have been selected. Two of them (Pravecchi and Burattana) are located in Lombardia, the other one (Bonizzato) in Veneto. All of them have a total area between 2 and 3 ha. Their financial statements have been analyzed considering prices and costs of five homogeneous horticultural products (lettuce, tomato, zucchini, eggplant, cucumber) for one year. Then, to investigate the economic convenience of the biodynamic choice in comparison with conventional method, with respect to prices, two different scenarios have been considered:

- Direct sales channels for both biodynamic and conventional farms. The sell prices observed in the biodynamic sample have been compared with prices in conventional agriculture as reported by literature (Corsi, 2009). These conventional farms are similar to our sample for small dimension, direct sales channel and cultivated land size.

- Direct sales channel for biodynamic farms and whole sale channel for conventional farms. In this case for conventional sector the whole sale prices data by ISMEA have been used.

In the first case we highlighted price differences between biodynamic and conventional production mainly due to the premium price related to the production differentiation. The second scenario reflects the price difference connected to different types of commercialization that represents the common situation of Italian market where the conventional production turns to common market channels while organic and biodynamic production are more and more strengthening alternatives channels and direct sale as reported by MIPAAF (2013). Finally, we realized a SWOT analysis with the aim to underline the main risks and possibilities related to the biodynamic conversion of conventional and organic firms, particularly as far as small farms in Po Valley.

\section{RESULTS AND DISCUSSION}

As shown in Figure 1, the distribution of biodynamic actors in Italy is not homogeneous. Some regions show a greater number of biodynamic farms, in particular Trentino Alto Adige, that is the most important region in biodynamic production in Italy. It should be due to the recent constitution of a biodynamic fruit producers organization named Biodynamik. Considering the altitudinal distribution of these farms, we find that the $46 \%$ of them are located in mountain regions, suggesting that biodynamic agriculture represents a valid alternative in marginal areas. More generally, the map shows a greater concentration of biodynamic activities in northern Italy: Trentino Alto Adige, Veneto, Piemonte, Lombardia, Emilia Romagna and Toscana gather 219 farms, representing 68\% of total number of biodynamic farms in Italy. It speaks to the strong economic difference existing between north and south part of Italy. In the north a highly urbanized territory and generally higher income levels have permitted the development of advanced and specific commercial channels for organic and biodynamic products. 


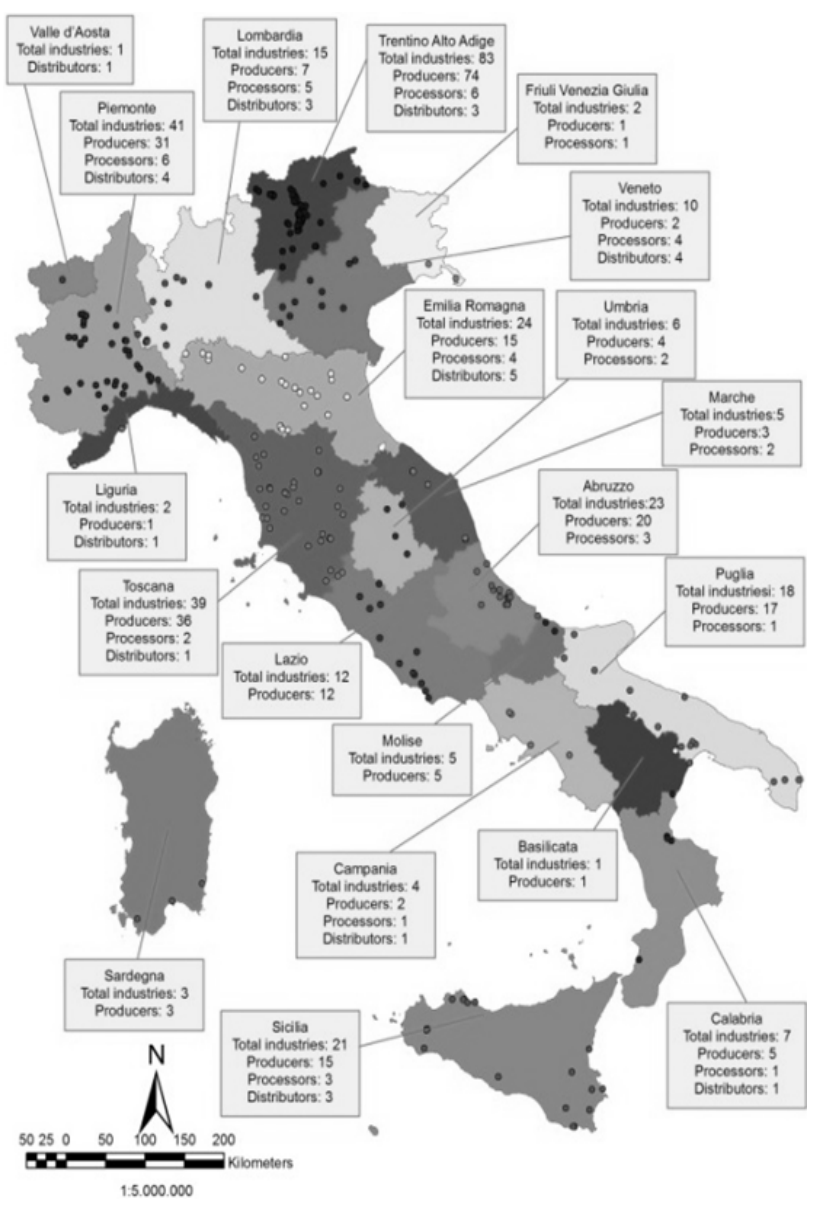

Figure 1. Maps of biodynamic farms distribution in Italy. Source: Demeter International data. Made by Department of Economics, Management and Quantitative Methods in ArcGIS, 2014.

\section{Farm survey}

The analysis of the production costs shows a pronounced difference among the three farms with regard to prices, costs and productivity, particularly with regard to tomatoes, cucumbers and eggplants. For example, comparing the unit costs, a great difference between Bonizzato farm and the other ones emerges, while at the same time Bonizzato's unit price for each product is considerably lower than those of the other two farms. With respect to the differences between biodynamic and conventional products, two very similar samples have been compared. They both consist of family farms with a similar structure (less than 1 ha for each horticultural product). Nevertheless, differences between them have been observed (Table 2). In particular regarding production costs higher values for biodynamic production have been registered in particular regarding tomatoes, zucchini and cucumbers. On the contrary, salads and eggplants show a lower cost in biodynamic production. Regarding prices we find two different situations: the case of biodynamic and conventional direct sale and biodynamic direct sales prices in comparison with the conventional wholesale prices. In the first case, though the similarity of commercial channel, biodynamic prices are higher, especially for tomatoes and lettuce. Only one product, cucumbers, shows an opposite trend, with higher prices in conventional production. A totally different scenario emerges in the 
second case, where direct sale prices of biodynamic were compared with wholesale prices of conventional produce taken from ISMEA for 2012-2013 period. In this case the difference between biodynamic direct sale prices and conventional wholesale prices that reaches peaks of more than $500 \%$ for cucumbers and eggplant, with an average percentage difference of 404\%. Finally a comparison between economic margins, obtained by the difference between prices and costs in all the three cases (Bonizzato farm, Burattana farm and Pravecchi farm), is represented in Figure 2. Biodynamic production shows positive margins in all types of products. In particular biodynamic eggplants, tomatoes and lettuce present the highest degree of positive margins in comparison with the other two samples: $+30,+59$ and $+60 \%$ respectively in comparison with conventional direct sales channel prices. Conventional production with a direct sales commercialization has the highest margins in cucumbers and zucchini production, +67 and $+44 \%$ in comparison with the biodynamic ones. The conventional production which use wholesales market channels show negative margins for all the products with the exception of cucumbers.

Table 2. Costs and prices of biodynamic and conventional products ( $€ \mathrm{~kg}^{-1}$ ). Source: ISMEA and direct surveys.

\begin{tabular}{lrrrrr}
\hline & Lettuce & Tomato & Zucchini & Cucumber & Eggplant \\
\hline Costs & & & & & \\
\hline Biodynamic & 1.2 & 0.8 & 1.1 & 0.8 & 0.6 \\
Conventional & 1.4 & 0.7 & 0.6 & 0.2 & 0.9 \\
$\Delta\left(€ \mathrm{~kg}^{-1}\right)$ & -0.2 & 0.1 & 0.5 & 0.5 & -0.3 \\
$\Delta \%$ Bio/Conv. & -12.3 & 14.9 & 92.3 & 239.7 & -33.4 \\
\hline Prices & & & & & \\
\hline Biodynamic & 1.9 & 2.0 & 1.9 & 1.8 & 2.1 \\
Conventional direct sale & 1.6 & 1.2 & 1.7 & 2.0 & 2.0 \\
$\Delta(€$ kg-1 $)$ & 0.2 & 0.8 & 0.2 & -0.2 & 0.2 \\
$\Delta \%$ Bio/conv. & 14.2 & 70.5 & 10.1 & -7.7 & 8.4 \\
\hline Biodynamic & 1.9 & 2.0 & 1.9 & 1.8 & 2.1 \\
Conventional wholesale & 0.4 & 0.5 & 0.5 & 0.3 & 0.3 \\
$\Delta(€$ kg-1 $)$ & 1.5 & 1.5 & 1.4 & 1.5 & 1.8 \\
$\Delta \%$ Bio/conv. & 374.4 & 287.8 & 291.8 & 500.0 & 566.7 \\
\hline
\end{tabular}




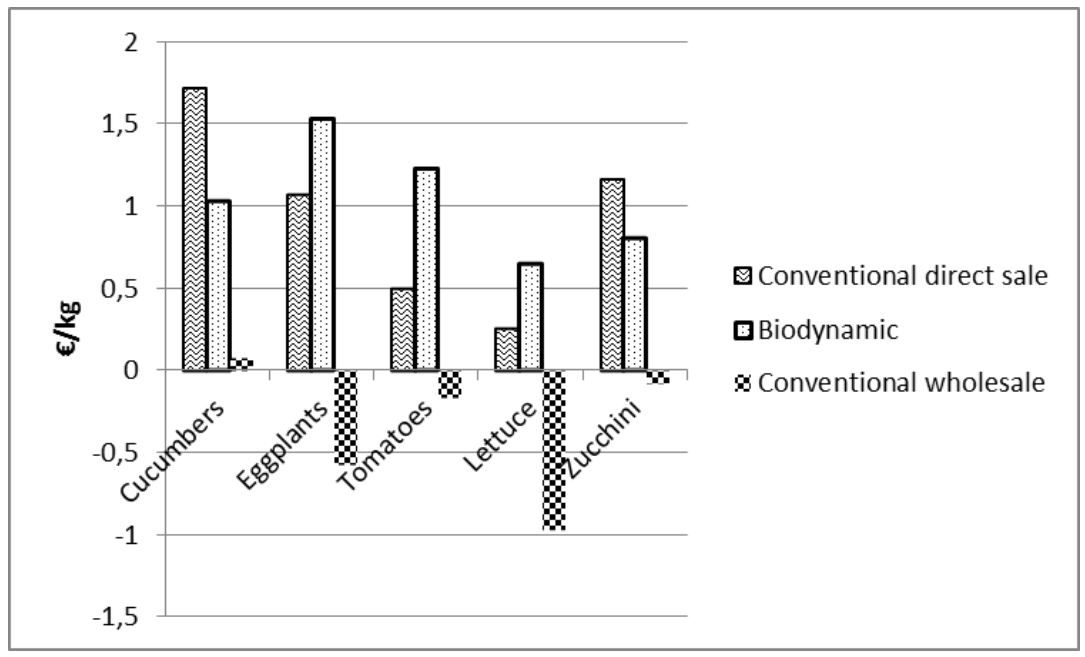

Figure 2. Comparison between economic margins (p-c).

\section{SWOT analysis}

\section{Strength.}

\section{Premium price.}

One of the most important strengths we can observe in biodynamic production is the presence of a strong premium price of biodynamic products that are able to meet environmentally friendly consumers target.

It is shown by the growth of organic and biodynamic production and consumption in the last years, despite its higher prices.

\section{Environmental benefits.}

Biodynamic production is a sustainable method which minimizes the use of agrochemicals and adopts some agricultural practices able to conserve land microbial population the organic matter enhancing soil fertility and water and fertilization use, reducing water pollution and greenhouse gasses emission.

\section{Demeter label.}

The presence of a certification organization for biodynamic products protects and guarantees their quality.

\section{Absence of start-up costs}

An organic farm has to take a conversion process of three years to obtain the biodynamic certification. During these three years it follows the biodynamic productive method and is subjected to periodic controls by Demeter International specialists. So the conversion process doesn't require expensive economic investments.

\section{Weaknesses.}

\section{High production costs.}

From our analysis biodynamic method appears to have higher production costs for three products than the conventional farming. This is mainly due to a higher level of labour costs. 
Lower yields.

Not necessarily and not always. However the lack of chemical products and not intensive agricultural practices could determine a lower production in comparison with conventional farms.

\section{Opportunities.}

Farm market and local food systems.

As happened in Europe, local $\mathrm{m}$ ts are developing in Italy too especially in urbanized regions in north Italy (Bio Re 2013; Ferrazzi et al., 2013). Even more farms are implementing direct sales and alternative sales channel supported by the growth of consumer attention to healthiness and quality of food.

\section{Political attention to sustainability.}

The new CAP towards 2020 focuses on the promotion of a more intelligent, sustainable and inclusive growth (EC, 2010).

\section{Threats.}

\section{Actual Lack of Information.}

This is an important issue in particular regarding consumers' consciousness about biodynamic method, its differences with organic farming and role and guarantee function of Demeter label.

\section{Uncertain market dynamic.}

Organic and biodynamic products have grown quickly in the last few years. The number of certified producers and specialized shops are increasing in number as is the availability of organic and biodynamic products in large grocery stores. Nevertheless in some European countries this expansion is slowing down and, though in Italy this trend appears confirmed also in 2014, economic crisis and market saturation could lead to a similar evolution.

\section{CONCLUSIONS}

The analysis allowed an overview of biodynamic agriculture in Italy, a sector that is showing good prospects in terms of demand and supply growth, especially in horticultural production. Nevertheless, the absence of statistical information still affects this new market. The direct survey confirmed the economic profitability of this method in particular regarding small farms; at the same time low convenience for these subjects in adopting conventional productive methods has emerged. In the future biodynamic method could represent a strategic opportunity for those small size farms that need higher revenues.

\section{Literature cited}

$<$ jrn>Brown, E., Dury, S., and Holdsworth, M. (2009). Motivations of consumers that use local, organic fruit and vegetable box schemes in Central England and Southern France. Appetite 53 (2), 183-188 http://dx.doi.org/10.1016/j.appet.2009.06.006. PubMed</jrn>

$<$ unknown>Corsi, A. (2009). I risultati economici ed i costi di produzione nell'agricoltura biologica piemontese, Rapporto di ricerca. Dipartimento di Economia dell'Università di Torino.</unknown>

$<$ bok>EC. (2010). The CAP towards 2020: Meeting the food, natural resources and territorial challenges of the future. Brussels, 18.11.2010.</bok>

$<$ bok>FAO. (2011). Biodiversity for Food and Agriculture. Contributing to Food Security and Sustainability in a Changing World (FAO: Rome, Italy). $<$ /bok $>$

$<$ conf $>$ Ferrazzi, G., Corsi, S., and Tosini, A. (2013). Local action group as driving force for the development of local agrifood systems. Paper presented at: International Scientific Conference: Rural Development.</conf>

$<$ jrn>Foley, J.A., Ramankutty, N., Brauman, K.A., Cassidy, E.S., Gerber, J.S., Johnston, M., Mueller, N.D., O’Connell, C., 
Ray, D.K., West, P.C., et al. (2011). Solutions for a cultivated planet. Nature 478 (7369), 337-342 http://dx.doi.org/10.1038/nature10452. PubMed</jrn>

$<$ jrn>Frisio, D.G., Ferrazzi, G., and Tesser, F. (2012). Competition: a strategic model for horticultural sector? The case of Lombardy Region. Acta Hortic. 960, 247-254 http://dx.doi.org/10.17660/ActaHortic.2012.960.35. </jrn> $<$ bok>Hazell, P. (2003). The Green Revolution. The Oxford Encyclopedia of Economic History. (Oxford, UK: Oxford University Press).</bok>

$<$ jrn>Hjelmar, U. (2011). Consumers' purchase of organic food products. A matter of convenience and reflexive practices. Appetite 56 (2), 336-344 http://dx.doi.org/10.1016/j.appet.2010.12.019. PubMed</jrn>

$<$ eref>ISMEA. (2013). Speciale biofach 2013. Report prodotti biologici. www.ismea.it</eref>

$<$ other>MIPAAF. (2013). Rete Rurale Nazionale 2007-2013. Bioreport 2013, L.</other>

<jrn>Pimentel, D., Hepperly, P., Hanson, J., Douds, D., and Seidel, R. (2005). Environmental, energetic, and economic comparisons of organic and conventional farming systems. Bioscience 55 (7), 573-582 http://dx.doi.org/10.1641/0006-3568(2005)055[0573:EEAECO]2.0.C0;2.</jrn>

$<j r n>$ Pingali, P.L. (2012). Green revolution: impacts, limits, and the path ahead. Proc. Natl. Acad. Sci. U.S.A. 109 (31), 12302-12308 http://dx.doi.org/10.1073/pnas.0912953109. PubMed</jrn>

$<$ irn>Pretty, J. (2008). Agricultural sustainability: concepts, principles and evidence. Philos. Trans. R. Soc. Lond., B, Biol. Sci. 363 (1491), 447-465 http://dx.doi.org/10.1098/rstb.2007.2163. PubMed </jrn>

$<$ jrn>Reganold, J.P., Palmer, A.S., Lockhart, J.C., and Macgregor, A.N. (1993). Soil quality and financial performance of biodynamic and conventional farms in new zealand. Science 260 (5106), 344-349 http://dx.doi.org/10.1126/science.260.5106.344. PubMed $</$ jrn>

<unknown>Regulation (2007). 2007/834/EC 0J L 189 of 20.7.2007, p.1-23.</unknown>

$<$ eref>SINAB. (2014). Bio in cifre 2014. ISMEA-CIHEAM-MIPAAF.http//: » www.sinab.it.</eref>

$<$ jrn $>$ Swift, M.J., Izac, M.N., and Van Noordwijk, M. (2004). Biodiversity and ecosystem services in agricultural landscapes - are we asking the right questions? Agric. Ecosyst. Environ. 104 (1), 113-134 http://dx.doi.org/10.1016/j.agee.2004.01.013.</jrn>

<jrn>Tilman, D., Balzer, C., Hill, J., and Befort, B.L. (2011). Global food demand and the sustainable intensification of agriculture. Proc. Natl. Acad. Sci. U.S.A. 108 (50), 20260-20264 http://dx.doi.org/10.1073/pnas.1116437108. $\underline{\text { PubMed }}</$ jrn>

<other>Tisdell, C. (2005). Sustainable Agriculture. Working paper No. 121 (The University of Queensland).</other $>$

$<$ irn>van Doorn, J., and Verhoef, P.C. (2011). Willingness to pay for organic products: differences between virtue and vice foods. Int. J. Res. Mark. 28 (3), 167-180 http://dx.doi.org/10.1016/i.ijresmar.2011.02.005. $</ j r n>$

$<$ jrn>Zander, K., and Hamm, U. (2010). Consumer preferences for additional ethical attributes of organic food. Food Qual. Prefer. 21 (5), 495-503 http://dx.doi.org/10.1016/i.foodqual.2010.01.006.</jrn> 